\title{
Influence of Store Managers' Climate of Concern for Employees on FLE Commitment, Customer Word-of-Mouth, and Store Traffic Growth: An Abstract
}

\author{
George D. Deitz, Emin Babakus, John D. Hansen, Thomas DeCarlo, \\ and Robert Evans Jr
}

\begin{abstract}
Establishing a favorable employee work environment is a critical factor in improving customer and financial performance (Brown and Leigh 1996; Schneider et al. 2002). Although it is generally agreed that store managers play an important role in enacting retail workplace environments, there is little empirical work that has examined relationships between manager characteristics, employee attitudes and behaviors, and store performance. Thus, the manner by which store managers' individualized interpretations of organizational strategies influence frontline employees' organizational attitudes is unclear. Addressing this gap, we examine how store managers' psychological climate of concern for employees impacts employee affective commitment, leading to higher store performance. Drawing from social exchange and agency theories, we offer support for a theorized model that was subsequently tested using survey data obtained from store managers, employees, and customers and supplemented by longitudinal store performance data. Study findings show store managers' idiosyncratic interpretations of workplace climate are pertinent in shaping FLE commitment. In addition, we provide evidence suggesting the positive effects of FLE commitment upon improvements in store traffic may be nonlinear. The robustness of the study findings are bolstered through the use of multisourced data and multilevel SEM analysis that takes into account the hierarchical structure of the data.
\end{abstract}

\author{
G. D. Deitz $(\bowtie) \cdot$ E. Babakus \\ The University of Memphis, Memphis, TN, USA \\ e-mail: gdeitz@memphis.edu; ebabakus@memphis.edu \\ J. D. Hansen · T. DeCarlo \\ University of Alabama-Birmingham, Birmingham, AL, USA \\ e-mail: jdhansen@uab.edu; tdecarlo@uab.edu \\ R. Evans Jr \\ Texas A\&M International, Laredo, TX, USA \\ e-mail: revans@taimu.edu
}

